\title{
Miniaturized Negative-Pressure Wound Therapy for Split-Thickness Skin Graft Donor Sites
}

\author{
Stuart L. Mitchell, MD ${ }^{1}$ Edward Ray, MD² Peter G. Cordeiro, MD² \\ ${ }^{1}$ Department of Orthopaedic Surgery, The Johns Hopkins University \\ School of Medicine, Baltimore, Maryland \\ 2 Plastic and Reconstructive Surgery Service, Department of Surgery, \\ Memorial Sloan Kettering Cancer Center, New York, New York

\begin{abstract}
Address for correspondence Peter G. Cordeiro, MD, Plastic and Reconstructive Surgery Service, Memorial Sloan Kettering Cancer Center, 1275 York Avenue, New York, NY 10065 (e-mail: cordeirp@mskcc.org).
\end{abstract}

J Reconstr Microsurg Open 2018;3:e46-e49.

\begin{abstract}
Background Multiple therapeutic options exist for the treatment of split-thickness skin graft (STSG) donor sites, but there is no clear consensus among surgeons about the best option. Negative-pressure wound therapy (NPWT) has rapidly gained in popularity since its invention. Recently, several miniaturized, single-patient NPWT (SP-NPWT) devices have become available. Compared with traditional NPWT devices, SP-NPWT devices are associated with equal wound healing capability and reliability, but offer several advantages. We present a series of 10 consecutive patients whose STSG donor sites were treated with a commercially available SP-NPWT device.

Methods We performed a retrospective review for 10 consecutive patients who underwent STSG procedures and were treated with SP-NPWT devices.

\section{Keywords}

- single-patient negative-pressure wound therapy

- split-thickness skin graft donor site

- vacuum-assisted closure

- PICO single-use NPWT system

Results From 2015 to 2017, 10 consecutive patients underwent oncologic reconstruction using STSG and had their donor sites treated with SP-NPWT devices. The SPNPWT dressing had been left in place for 2 weeks after surgery. The average donor site area measured $80 \mathrm{~cm}^{2}$ (range: $76-106 \mathrm{~cm}^{2}$ ). In all 10 patients, the donor sites healed uneventfully and with no complications.

Conclusion Off-the-shelf, miniaturized, SP-NPWT systems appear to be at least as effective as traditional dressings for STSG donor sites and require no maintenance (skilled nursing or dressing changes). Compared with larger and less portable standard NPWT devices, SP-NPWT dressing systems provide a potential cost benefit as well as enhanced convenience and portability.
\end{abstract}

Skin grafting is one of the procedures most commonly performed by plastic and reconstructive surgeons. Harvesting a split-thickness skin graft (STSG) removes the entire epidermal layer as well as a partial-thickness dermal layer that provides the structural support for the graft. The partial-thickness wound that is created at the donor site heals by re-epithelialization via migration of keratinocytes (epidermal cells). ${ }^{1}$ To ensure robust healing by secondary intention, the wound should be protected from desiccation and mechanical trauma. There are a variety of methods used to treat STSG donor sites, as indicated in a recent systematic review of wound dressings for skin graft donor sites. ${ }^{2}$ Among the non-occlusive dressings, the most commonly used were Xeroform (DeRoyal Industries, Inc., Powell, TN), Scarlet Red (Kendall Healthcare, Mansfield, MA), and Jelonet (Smith \& Nephew, Hull, United Kingdom), whereas Kaltostat (ConvaTec, Oklahoma City, OK), Opsite (Smith \& Nephew, Hull, United Kingdom), DuoDERM (ConvaTec, Oklahoma City, OK), and Allevyn (Smith \& Nephew, Hull, United Kingdom) were the most frequently used occlusive or absorbent dressings. ${ }^{2}$ received

February 14, 2018 accepted after revision June 18, 2018
DOI https://doi.org/

$10.1055 / \mathrm{s}-0038-1668561$ ISSN 2377-0813.
Copyright $\odot 2018$ by Thieme Medical

Publishers, Inc., 333 Seventh Avenue, New York, NY 10001, USA. Tel: +1(212) 584-4662.
License terms

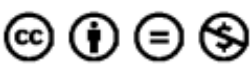




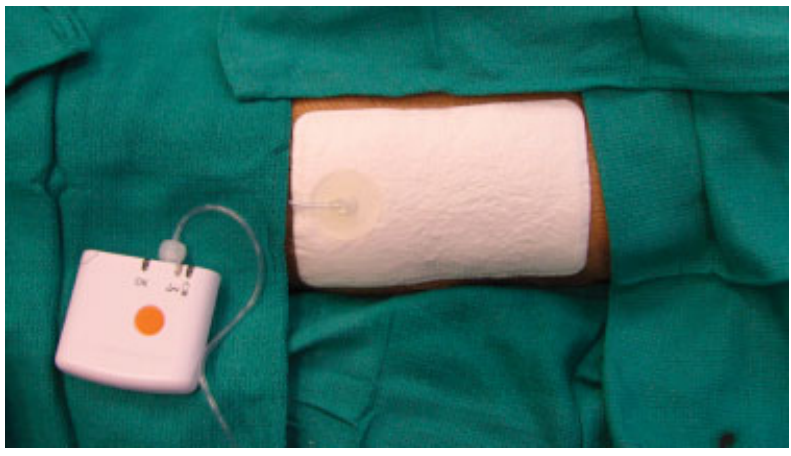

Fig. 1 STSG donor site with miniaturized, SP-NPWT device in place. SP-NPWT, single-patient-negative-pressure wound therapy; STSG, split-thickness skin graft.

The use of negative-pressure wound therapy (NPWT) has increased rapidly since it was first described in $19977^{3,4}$ There are many indications ${ }^{1,5-7}$ now for the use of NPWT, including stabilization and bolstering of STSGs, ${ }^{8-14}$ and as a dressing for skin graft donor sites. ${ }^{15,16}$ Over the past several years, several miniaturized, disposable, single-patient NPWT (SP-NPWT) devices have been introduced. ${ }^{5,6,17-21}$ These devices have the potential to simplify wound care in the management of skin graft donor sites in the outpatient setting. The authors describe a series of 10 patients with STSG donor site wounds treated with an off-the-shelf, miniaturized, SP-NPWT device.

\section{Methods}

Our institutional review board approved a retrospective review of our patient database.
From 2015 to 2017, the donor sites of 10 consecutive patients who underwent STSG procedures were treated with SP-NPWT devices (PICO System, Smith \& Nephew, Hull, UK) by a single surgeon (P.G.C.). The skin grafts were each harvested using an electric dermatome (with a 3-inch $(7.62 \mathrm{~cm})$ guard) set to 0.013 -inch $(0.033 \mathrm{~cm})$ thickness. The donor sites were dressed with either a fine-mesh gauze impregnated with 3\% bismuth tribromophenate and petrolatum (Xeroform, DeRoyal Industries, Inc., Powell, TN) or a knitted cellulose acetate fabric impregnated with petrolatum (Adaptic, Acelity, San Antonio, $\mathrm{TX}$ ) and then were covered with a $15 \times 30$-cm SP-NPWT dressing (-Fig. 1). Patients were sent home with the dressing in place, which had been left in place for 2 weeks and was then removed in the outpatient clinic. The SP-NPWT device remained attached until the battery ran out (usually by postoperative day 7). The donor site was assessed for re-epithelialization 2 weeks postoperatively.

\section{Results}

All 10 patients underwent oncologic reconstruction at remote sites requiring STSG. The mean age of the patients was 55 years (range: 28-80 years), and five were male. The average dimension of the thigh donor site was $80 \mathrm{~cm}^{2}$ (range: $76-106 \mathrm{~cm}^{2}$ ). In all 10 patients, the donor sites had complete re-epithelialization within 2 weeks. There were no wound healing complications at the STSG donor site in any of the patients ( - Fig. $2 \mathbf{A}$ and $\mathbf{B}$ ).

\section{Discussion}

Skin-graft donor site wounds may be treated using one of many different dressings, including NPWT. ${ }^{15,16}$ Dressing STSG donor sites with a vacuum-assisted closure (VAC)
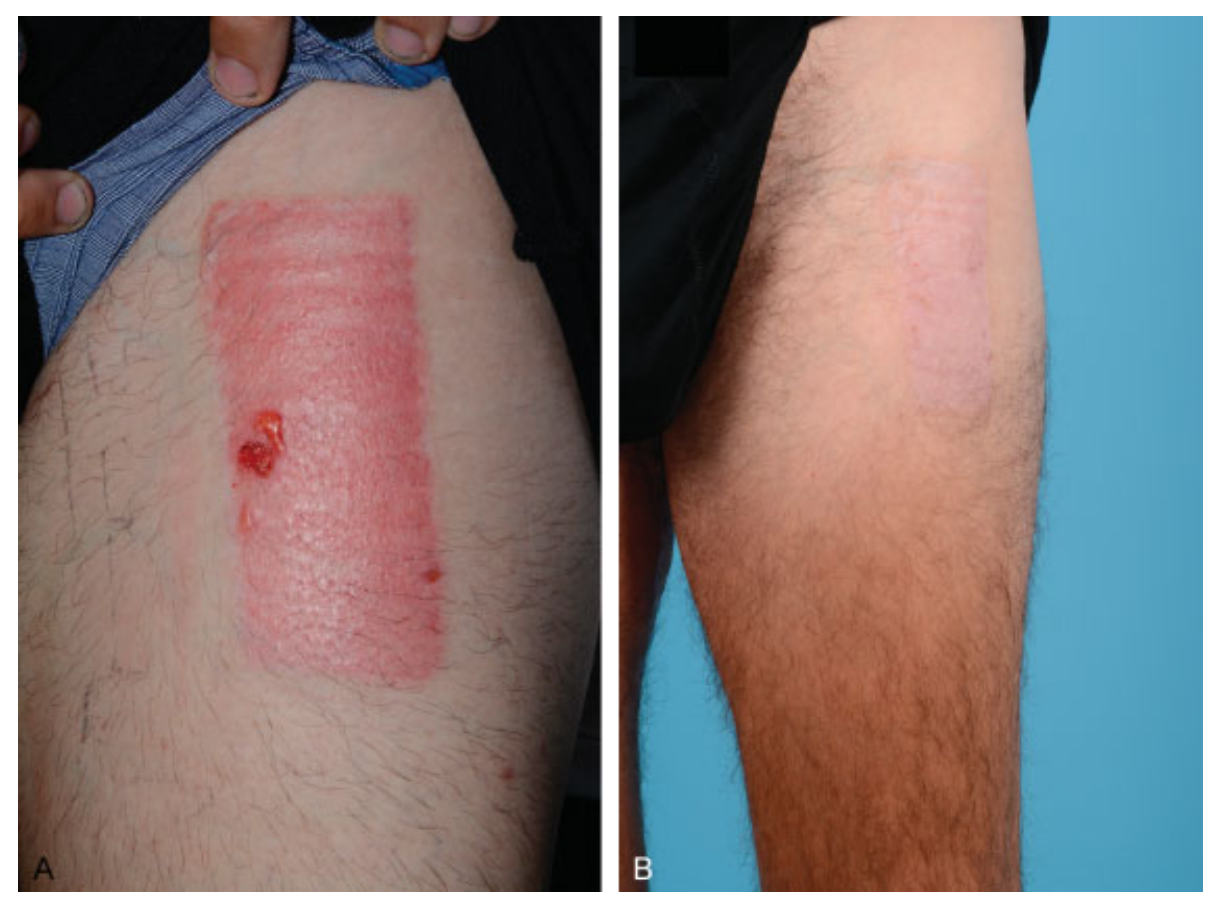

Fig. 2 Healed STSG donor site following treatment with miniaturized, SP-NPWT device at 2 weeks (A) and at 5 months (B). SP-NPWT, singlepatient-negative-pressure wound therapy; STSG, split-thickness skin graft. 
device has several benefits over traditional dressings, including collection of excess wound exudate, convenience, improved wound healing, and decreased hospital length of stay (LOS). Since the release of off-the-shelf, disposable, miniaturized SP-NPWT devices, such as the PICO System (Smith \& Nephew, Hull, UK), many surgeons have begun to use these SP-NPWT devices for several indications $s^{5,6,17-21}$ that were previously treated with standard VAC devices. Compared with traditional NPWT devices, SP-NPWT devices are associated with equal wound-healing capability ${ }^{17,21}$ and reliability, ${ }^{5,6}$ but have unique benefits.

Following STSG harvest, a significant amount of exudate typically drains from the donor site. When traditional dressings are applied to these wounds, excess fluid may leak from the dressing and can present a management problem for patients and caregivers, necessitating frequent, painful dressing changes. Although it was not formally measured with the use of a standardized patient-reported outcome instrument, the patients in our series did seem to report less pain as compared with patients treated with traditional dressings. Standard NPWT dressings collect these exudates in a canister attached to the device. The PICO System is able to manage the exudate through a combination of an absorbent dressing layer and evaporative loss of the fluid. ${ }^{17}$ Since these miniaturized systems do not require a canister, they are much more compact than the standard devices used for NPWT, which allows for increased patient mobility and comfort. ${ }^{10,17}$ This is in contrast to other miniaturized, SP-NPWT systems that do require the use of a small canister, and thus are less able to handle moderate amounts of exudate without being emptied. Both traditional and disposable NPWT devices used to treat STSG donor site wounds may be used continuously for up to 14 days without the need to be changed. No specialty nursing services are required to change dressings or monitor therapy as an outpatient, and patient discomfort is minimized.

NPWT has also been shown to accelerate the healing of STSG donor sites. Nuutila et $\mathrm{al}^{16}$ examined gene expression and exudate content and found significant induction of genes involved in inflammation and cell proliferation, along with significant suppression of cell differentiation genes on postoperative day 7 in patients treated with NPWT, compared with control. They concluded that short-term use of NPWT improves healing by promotion of inflammation that is associated with cell migration and wound healing, but may inhibit cell differentiation with longer term use. Genecov et al ${ }^{15}$ compared the rate of re-epithelialization between one STSG donor site treated with NPWT and another site treated with vapor-permeable dressing. The comparison was initially performed in a porcine model $(n=4)$, with the second site in the same subject (serving as an internal control), then subsequently in humans $(n=10)$. They reported more rapid re-epithelialization in 70\% of patients treated with NPWT by postoperative day $7(p<0.013)$. In the treatment of other types of wounds, NPWT has also been shown to promote wound granulation and decrease interstitial edema, thereby increasing tissue perfusion. ${ }^{4,22}$ Notably, wound healing with the use of SP-NPWT seems to be at least equivalent to standard NPWT using full-sized devices. ${ }^{17,21}$ SP-NPWT devices have also been shown to decrease postoperative wound complications, compared with standard dressings. ${ }^{18}$

Standard NPWT techniques utilize a device that is rented by the healthcare facility or by the patient in the outpatient setting. When applied in the inpatient setting, patients typically remain in the hospital until insurance authorization has been obtained. In comparison, patients with an off-theshelf, ultra-portable SP-NPWT dressing may be discharged without insurance approval or the need for specialty nursing services. This leads to reduced LOS in the hospital, compared with patients treated with traditional dressings ${ }^{6,18,23}$ and traditional NPWT devices ${ }^{20}$ and has the potential to decrease healthcare costs. The PICO System costs around \$217 which is substantially more than the traditional dressing at \$54 per use; however, the majority patients require at least one dressing change with the traditional dressings. Thus, traditional dressings cost closer to $\$ 100$ per patient; however, the cost of skilled nursing necessary to perform the dressing change is not included in this amount.

\section{Conclusion}

SP-NPWT is useful in the management of donor sites following the harvest of STSG. This option appears to be at least as effective as traditional donor site dressings and requires no maintenance, which can be both painful and messy. Compared with larger and less portable standard NPWT devices, the SP-NPWT dressing systems provide a potential cost benefit as well as enhanced convenience and portability.

\section{Funding}

This research was funded, in part, through the National Institutes of Health/National Cancer Institute (NIH/NCI) Cancer Center Support Grant P30 CA008748.

\section{Conflict of Interest}

None.

\section{References}

1 Thorne CH, Chung KC, Gosain AK, et al. Grabb and Smith's Plastic Surgery. 7th ed. Philadelphia, PA: Lippincott Wiliams \& Wilkins; 2013

2 Voineskos SH, Ayeni OA, McKnight L, Thoma A. Systematic review of skin graft donor-site dressings. Plast Reconstr Surg 2009;124(01): 298-306

3 Morykwas MJ, Argenta LC, Shelton-Brown EI, McGuirt W. Vacuum-assisted closure: a new method for wound control and treatment: animal studies and basic foundation. Ann Plast Surg 1997;38(06):553-562

4 Argenta LC, Morykwas MJ. Vacuum-assisted closure: a new method for wound control and treatment: clinical experience. Ann Plast Surg 1997;38(06):563-576

5 Payne C, Edwards D. Application of the single use negative pressure wound therapy device (PICO) on a heterogeneous group of surgical and traumatic wounds. Eplasty 2014;14:e20

6 Selvaggi F, Pellino G, Sciaudone G, et al. New advances in negative pressure wound therapy (NPWT) for surgical wounds of patients affected with Crohn's disease. Surg Technol Int 2014;24:83-89

7 Huang C, Leavitt T, Bayer LR, Orgill DP. Effect of negative pressure wound therapy on wound healing. Curr Probl Surg 2014;51(07): 301-331 
8 Trop M, Schintler M, Urban E, Roedl S, Stockenhuber A. Are 1:4 mesh and donor site contraindications for vacuum-assisted closure device? J Trauma 2006;61(05):1267-1270

9 Waltzman JT, Bell DE. Vacuum-assisted closure device as a splitthickness skin graft bolster in the burn population. J Burn Care Res 2014;35(05):e338-e342

10 Sposato G, Molea G, Di Caprio G, Scioli M, La Rusca I, Ziccardi P. Ambulant vacuum-assisted closure of skin-graft dressing in the lower limbs using a portable mini-VAC device. Br J Plast Surg 2001;54(03):235-237

11 Llanos S, Danilla S, Barraza C, et al. Effectiveness of negative pressure closure in the integration of split thickness skin grafts: $\mathrm{a}$ randomized, double-masked, controlled trial. Ann Surg 2006;244 (05):700-705

12 Petkar KS, Dhanraj P, Kingsly PM, et al. A prospective randomized controlled trial comparing negative pressure dressing and conventional dressing methods on split-thickness skin grafts in burned patients. Burns 2011;37(06):925-929

13 Azzopardi EA, Boyce DE, Dickson WA, et al. Application of topical negative pressure (vacuum-assisted closure) to split-thickness skin grafts: a structured evidence-based review. Ann Plast Surg 2013;70(01):23-29

14 Moisidis E, Heath T, Boorer C, Ho K, Deva AK. A prospective, blinded, randomized, controlled clinical trial of topical negative pressure use in skin grafting. Plast Reconstr Surg 2004;114(04):917-922

15 Genecov DG, Schneider AM, Morykwas MJ, Parker D, White WL, Argenta LC. A controlled subatmospheric pressure dressing increases the rate of skin graft donor site reepithelialization. Ann Plast Surg 1998;40(03):219-225

16 Nuutila K, Siltanen A, Peura M, et al. Gene expression profiling of negative-pressure-treated skin graft donor site wounds. Burns 2013;39(04):687-693

17 Malmsjö M, Huddleston E, Martin R. Biological effects of a disposable, canisterless negative pressure wound therapy system. Eplasty 2014;14:e15

18 Pellino G, Sciaudone G, Candilio G, Campitiello F, Selvaggi F, Canonico $S$. Effects of a new pocket device for negative pressure wound therapy on surgical wounds of patients affected with Crohn's disease: a pilot trial. Surg Innov 2014;21(02):204-212

19 Holt R, Murphy J. PICO ${ }^{\mathrm{TM}}$ incision closure in oncoplastic breast surgery: a case series. Br J Hosp Med (Lond) 2015;76(04):217-223

20 Gabriel A, Thimmappa B, Rubano C, Storm-Dickerson T. Evaluation of an ultra-lightweight, single-patient-use negative pressure wound therapy system over dermal regeneration template and skin grafts. Int Wound J 2013;10(04):418-424

21 Isaac AL, Rose J, Armstrong DG. Mechanically powered negative pressure wound therapy as a bolster for skin grafting. Plast Reconstr Surg Glob Open 2014;2(02):e103

22 Demaria M, Stanley BJ, Hauptman JG, et al. Effects of negative pressure wound therapy on healing of open wounds in dogs. Vet Surg 2011;40(06):658-669

23 Khanbhai M, Fosah R, Oddy MJ, Richards T. Disposable NPWT device to facilitate early patient discharge following complex DFU. J Wound Care 2012;21(04):180-182 